\title{
Sporadic Creutzfeldt-Jakob disease: Real-Time Quaking-Induced Conversion (RT-QuIC) assay represents a major diagnostic advance
}

\author{
Federico Angelo Cazzaniga*, Edoardo Bistaffa*, Chiara Maria Giulia De Luca, Antonio Indaco, Giuseppe Bufano, \\ Giorgio Giaccone, Fabio Moda
}

Fondazione IRCCS Istituto Neurologico Carlo Besta, Division of Neurology 5-Neuropathology, Milan, Italy

*These authors equally contributed to this work

\begin{abstract}
Sporadic Creutzfeldt-Jakob disease (sCJD) is a rare and fatal neurodegenerative disorder with an incidence of 1.5 to 2 cases per million population/year. The disease is caused by a proteinaceous infectious agent, named prion (or $\mathrm{PrPs}$ ), which arises from the conformational conversion of the cellular prion protein $\left(\mathrm{Pr}^{\mathrm{PC}}\right)$. Once formed, $\mathrm{PrP}^{\mathrm{Sc}}$ interacts with the normally folded $\mathrm{Pr}^{\mathrm{PC}}$ coercing it to undergo similar structural rearrangement. The disease is highly heterogeneous from a clinical and neuropathological point of view. The origin of this variability lies in the aberrant structures acquired by $\mathrm{PrP}^{\mathrm{Sc}}$. At least six different $\mathrm{sCJD}$ phenotypes have been described and each of them is thought to be caused by a peculiar $\operatorname{PrP}^{\mathrm{Sc}}$ strain. Definitive SCJD diagnosis requires brain analysis with the aim of identifying intracerebral accumulation of $\operatorname{PrP}^{\mathrm{Sc}}$ which currently represents the only reliable biomarker of the disease. Clinical diagnosis of SCJD is very challenging and is based on the combination of several clinical, instrumental and laboratory tests representing surrogate disease biomarkers. Thanks to the advent of the ultrasensitive Real-Time Quaking-Induced Conversion (RT-QuIC) assay, $\operatorname{PrP}^{\mathrm{Sc}}$ was found in several peripheral tissues of SCJD patients, sometimes even before the clinical onset of the disease. This discovery represents an important step forward for the clinical diagnosis of sCJD. In this manuscript, we present an overview of the current applications and future perspectives of RT-QuIC in the field of sCJD diagnosis.
\end{abstract}

Key words: Sporadic Creutzfeldt-Jakob disease; olfactory mucosa; cerebrospinal fluid; neurodegeneration; peripheral biomarkers; prion; seeding aggregation assays.

Correspondence: Giorgio Giaccone, Fondazione IRCCS Istituto Neurologico Carlo Besta, Division of Neurology 5 - Neuropathology, Via G. Celoria 11, 20133 Milan, Italy. E-mail: giorgio.giaccone@istituto-besta.it

Contributions: FAC, EB, manuscript drafting, tables and figures preparation; CMGD, AI, GB, contribution to manuscript drafting; FM, GG, manuscript concept and critical revision. All the authors have read and approved the final version of the manuscript and agreed to be accountable for all aspects of the work.

Conflict of interest: The authors declare that they have no competing interests, and all authors confirm accuracy. 


\section{Molecular and neuropathological classification of SCJD subtypes}

Among human prion diseases, sporadic Creutzfeldt-Jakob disease (sCJD) is the most common form affecting 1-2 individuals/million per year with similar distribution in males and females. ${ }^{1}$ The age at onset is most frequently between 55 and 75 years. ${ }^{2}$ sCJD presents with variable disease subtypes characterized by peculiar clinical and neuropathological features. In the past, other than the classical and more common subtypes, some clinical variants such as the Heidenhain, the myoclonic, the thalamic, the cerebellar or ataxic, and the panencephalopathic forms were reported. ${ }^{3-6}$ In general, sCJD cases present as multifocal and rapidly progressive encephalopathies with dementia, cerebellar ataxia, myoclonus while the progression of the disease results in an akinetic and mute state and the death occurs generally within 6 months after the disease onset. ${ }^{1}$ The common mechanism underlying these pathologies is the spontaneous conformational conversion of the cellular prion protein $\left(\mathrm{PrP}^{\mathrm{C}}\right)$ into an abnormally folded conformer named prion or $\mathrm{PrP}^{\mathrm{Sc}}$. This latter propagates in an autocatalytic manner in the brain by converting the $\mathrm{PrPC}^{\mathrm{C}}$ into the pathological isoform.

$\mathrm{PrP}^{\mathrm{C}}$ is a glycosylphosphatidylinositol (GPI) anchored protein highly expressed in the central nervous system (CNS) and encoded by the PRNP gene located on chromosome 20 in humans. ${ }^{7,8}$ After its synthesis in the rough endoplasmic reticulum, $\operatorname{Pr}^{\mathrm{C}}$ undergoes post-translational modifications comprising the C-terminal addition of the GPI anchor, the formation of a disulfide bridge between two C-terminal cysteine residues (Cys179-Cys214) and the Nlinked glycosylation at asparagine residues (Asn181-Asn197). ${ }^{9}$
These oligosaccharides are further modified in the Golgi apparatus to produce complex-type chains enriched in sialic acid important for the synaptic localization of $\operatorname{PrP}^{\mathrm{C}} .{ }^{10,11}$ The different degrees of $\mathrm{PrP}^{\mathrm{C}}$ glycosylation give rise to three isoforms of the protein: the diglycosylated $(70 \%)$, the mono-glycosylated $(25 \%)$ and the un-glycosylated (5\%) species. ${ }^{10,12}$ All these isoforms are rich in $\alpha$-helices structures, soluble in detergent and are sensitive to proteolytic digestion with proteinase $\mathrm{K}(\mathrm{PK})$. Conversely, $\mathrm{PrP}^{\mathrm{Sc}}$ is less soluble in detergent, has higher amount of $\beta$-sheet structures and is partially resistant to PK digestion. The limited proteolysis leads to the generation of N-terminal truncated fragments of di-, mono- and un-glycosylated $\mathrm{PrP}^{\mathrm{Sc}}$ that migrate at lower molecular weights compared to those of $\operatorname{PrP}^{\mathrm{C}} .{ }^{13}$ Moreover, the un-glycosylated band of $\mathrm{PrP}^{\mathrm{Sc}}$ can acquire two distinct molecular weights: 21 or $19 \mathrm{kDa}$

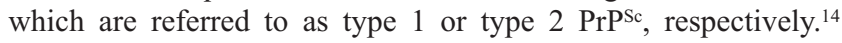
Neuropathologically, the main hallmarks of SCJD are spongiform changes, astoglial activation, neuronal loss and accumulation of $\mathrm{PrPSc}^{\mathrm{S}}$ (Figure 1 and Figure 2). ${ }^{15}$

At present, $\mathrm{PrP}^{\mathrm{Sc}}$ is the only disease-specific biomarker for SCJD and the definite diagnosis can be formulated post-mortem by biochemical and neuropathological analyses aimed at identifying the $\mathrm{PrP}^{\mathrm{Sc}}$ accumulation in the CNS (Figure 2). ${ }^{16,17}$

It is well known that $\mathrm{PrP}^{\mathrm{Sc}}$ can acquire different abnormal conformations, named strains. The peculiar conformation of each strain can be faithfully transmitted to the host $\mathrm{PrP}^{\mathrm{C}}$ and are believed to be responsible for the heterogeneity of prion diseases, in terms of tissue tropism, incubation period, clinical signs, neuropathological changes and interspecies transmission properties. ${ }^{18-}$ ${ }^{21}$ In 1999, Parchi and colleagues ${ }^{22}$ classified SCJD in six major subtypes by correlating the clinical manifestations with the polymorphisms at codon 129 of the PRNP gene, i.e. methionine (M) or
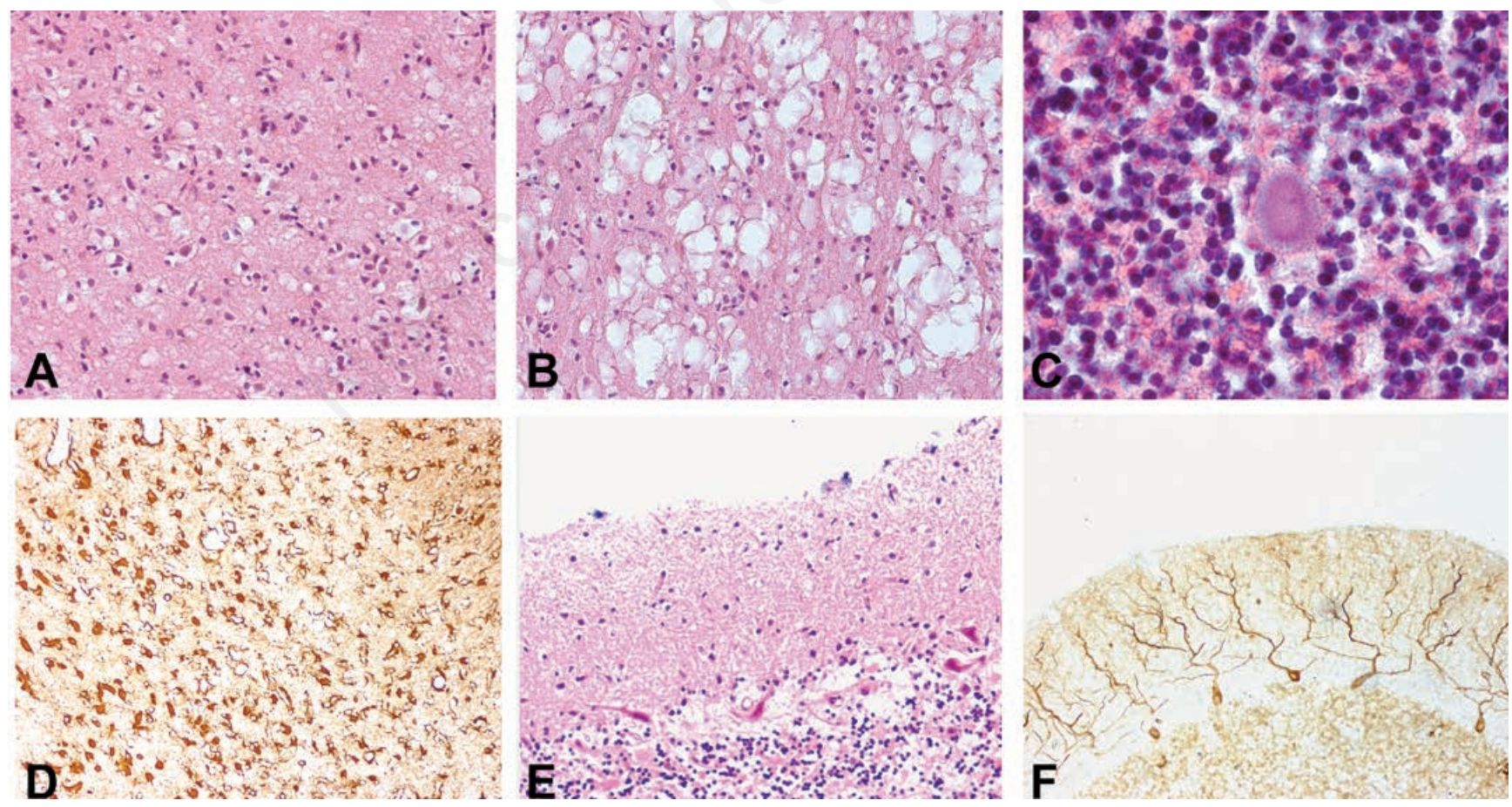

Figure 1. Creutzfeldt-Jakob disease, hallmark neuropathologic lesions. Spongiform changes may appear as small vacuoles (A) diffusely present in grey matter (H\&E, cerebral cortex, 20x) or large, confluent vacuolar lesions (B) typical of the MM2-C (cortical) subtype (H\&E, cerebral cortex, 20x). Kuru plaques (C) small aggregates of PrP with the tinctorial and optical properties of amyloid are typically found in the cerebellum in MV2 subtype (H\&E, 60x). Astrogliosis (D) may be severe in all subtypes of Creutzfeldt-Jakob disease (glial fibrillary acidic protein immunohistochemistry, 10x). Neuronal loss $(\mathrm{E})$ is usually very severe in the cerebral cortex, basal ganglia and cerebellum (H\&E, cerebellum) but may be mild in some cases (F) (microtubule associated protein 2 immunohistochemistry; 10x). 
valine (V), and the electrophoretic mobility of the un-glycosylated $\mathrm{PrP}^{\mathrm{Sc}}$ isoform in the brain after digestion with $\mathrm{PK}$ (type 1 or type 2 $\mathrm{PrP}^{\mathrm{Sc}}$ ). These findings demonstrated that the presence of $\mathrm{M}$ or $\mathrm{V}$ at codon 129 of $\operatorname{PrP}^{\mathrm{C}}$, as well as other still unknown factors, could modulate the structural rearrangement of $\mathrm{PrP}^{\mathrm{C}}$ during misfolding, thus promoting the $\mathrm{PrP}^{\mathrm{Sc}}$ strains variability. ${ }^{23-26}$ In addition, compelling evidence suggests that, in some SCJD cases, the CNS contains a mixture of $\mathrm{PrP}^{\mathrm{Sc}}$ strains (e.g., $\mathrm{MM} 1+2, \mathrm{VV} 1+2$ and MV1+2), which make the classification of the disease even more challenging (as discussed in the next paragraphs). ${ }^{14,27-29}$

The main pathological characteristics of each SCJD subtype are summarized in Table 1.

\section{MM1 and MV1 subtype}

MM1 is the most common form of SCJD ( $67 \%$ of all cases) while MV1 cases are rare (3\%). Western blot analysis shows, for both subtypes, type $1 \mathrm{PrPsc}^{\mathrm{Sc}}$ and a glycoform pattern characterized by the predominance of the mono-glycosylated band. Despite the difference at codon 129 of PRNP, MM1 and MV1 cases share many pathological features. MM1/MV1 CJD patients present with the myoclonic (or classic CJD) and the Heidenhain's variant. ${ }^{22}$ The mean age at onset of the disease is 66 years with an average clinical duration of 4 months. Clinical manifestations include cognitive impairment with memory loss and confusion/disorientation, depression, anxiety, psychosis and gait or limb ataxia. ${ }^{30}$ Neuropathologically, the brain of these patients shows spongiosis with fine vacuoles. The basal ganglia, thalamus and cerebellum are less affected than the cerebral neocortex. The hippocampal cortex and brain stem are largely spared. The pattern of $\operatorname{PrP}^{\mathrm{Sc}}$ deposition is synaptic and mainly affects the cerebral cortex while the cerebellum, the basal ganglia and thalamus are less involved (Figure 2 A,B). ${ }^{31}$ Moreover, the amount of PrPsc signal directly correlates with the severity of spongiosis.

\section{VV2 subtype}

The VV2 subtype corresponds to the cerebellar or ataxic variant and occurs in $15 \%$ of sCJD cases. The Western blot profile shows type $2 \mathrm{PrP}^{\mathrm{Sc}}$ with a preponderance of the mono-glycosylated isoform. The mean age at onset is 64 years (with a range of 40-83 years) and the clinical duration is about 7 months. ${ }^{32}$ Ataxia is the commonest early clinical feature accompanied by cognitive impairment and oculomotor signs while myoclonus is less frequent. In the late stages of the disease patients exhibit dementia, myoclonus and pyramidal signs. Neuropathologically, the spongiosis preferentially affects the deep layers of the frontal and occipital cortex, the entorhinal cortex and the hippocampus. ${ }^{31}$ Cerebral neocortex may be relatively spared particularly in cases with rapid courses. The cerebellar cortex is atrophic, with abundant $\mathrm{PrPSc}$ deposits characterized by a focal and plaque-like pattern that are negative for Congo Red and Thioflavin-S (amyloid stains). In addition, strong $\mathrm{PrP}^{\mathrm{Sc}}$ deposition often occurs around neuronal perikarya in the cerebral cortex (Figure 2 C,D). The distribution of $\mathrm{PrP}^{\mathrm{Sc}}$ immunostaining is affected by the disease duration. In cases with shorter disease duration, $\mathrm{PrPsc}^{\mathrm{Sc}}$ involve diffusely the gray-matter region except for the neocortex which is affected only in patients with longer disease duration. ${ }^{33}$

\section{MV2 subtype}

MV2 sCJD subtype is phenotypically and biochemically similar to VV2 cases (type $2 \mathrm{PrP}^{\mathrm{Sc}}$ and predominance of the mono-glycosylated form) and accounts for $10 \%$ of all sCJD. The mean age at onset is 65 years with a range of $36-83$ years while the disease
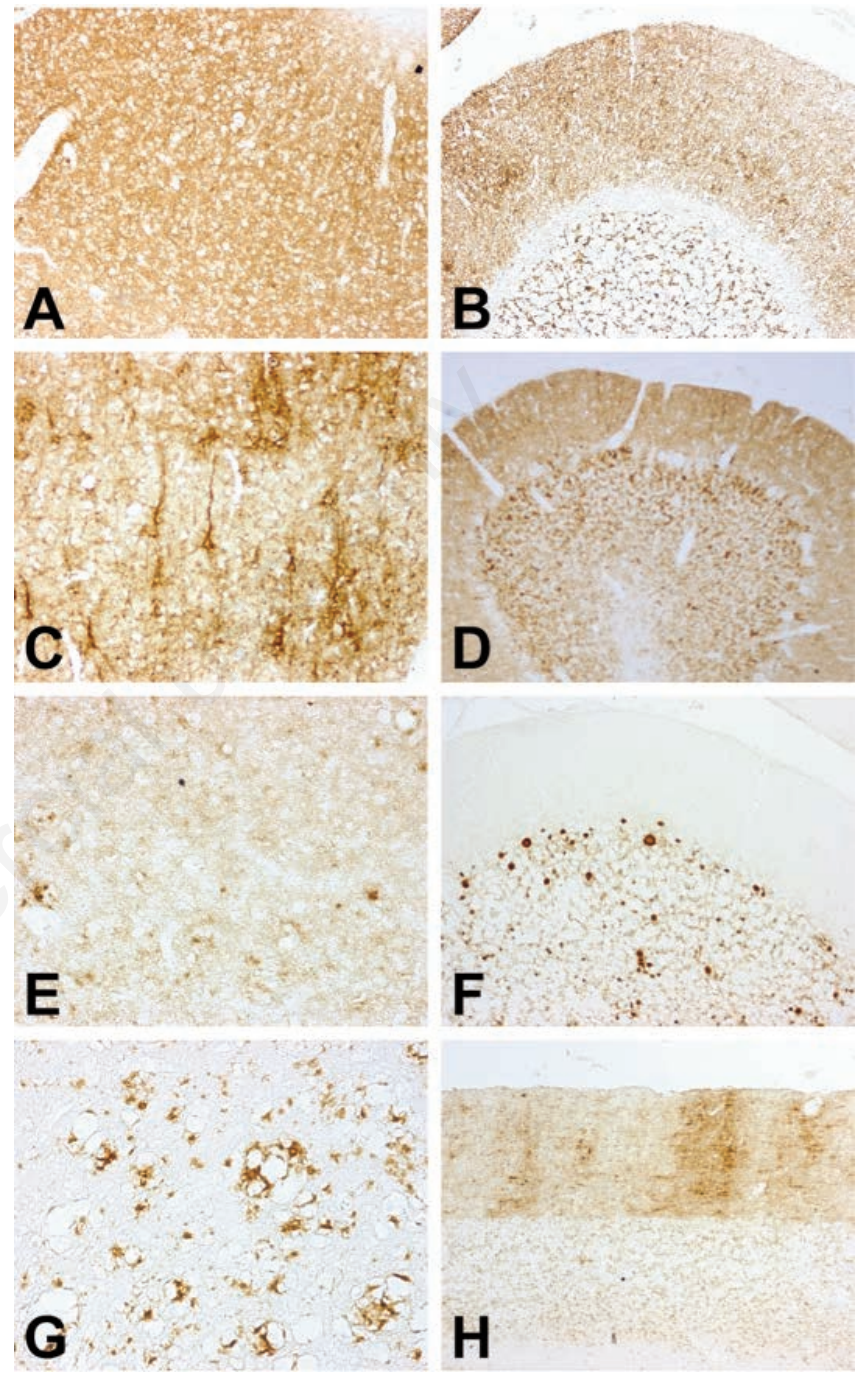

Figure 2. Creutzfeldt-Jakob disease, patterns of pathological $\operatorname{PrP}$ deposition (PrP immunohistochemistry using 3F4 monoclonal antibody). In MM/MV1 subtype PrP deposition is mainly of synaptic type and appears as homogeneous, finely granular immunoreactivity in the neuropil of the cerebral cortex $(\AA)(10 x)$, while in the cerebellum is finely granular in the molecular layer while forming coarser deposits in the granular layer (B) (10x). In VV2 subtype PrP deposition often decorates the boundaries of pyramidal neurons of the cerebral cortex $(C)(10 x)$, while in the cerebellum plaque-like deposition takes is common in the granular layer (D) (10x). In most of the patients with the MM2 subtype PrP deposition takes variable aspects in the cerebral cortex (E) $(20 x)$, while the typical feature is the presence of Kuru plaques, small aggregates of PrP with the tinctorial and optical properties of amyloid, in the cerebellum (F) (10x). MM2-C (cortical) subtype is characterized by $\operatorname{PrP}$ immunoreactivity more intense at the rims of the large vacuoles of spongiosis in the cerebral cortex (G) $(20 x)$, while the cerebellum is usually relatively spared $(H)$ $(10 x)$. 
duration is significantly longer than VV2 with a mean of 17 months (range of 5-72 months). Early manifestations of the disease include oculomotor abnormalities, memory loss, behavioral disturbances and signs of the peripheral nervous system or medullary involvement. In MV2 cases ataxia is the most common presenting sign and cognitive deterioration, myoclonus and pyramidal signs, aphasia and apraxia arise during disease progression. The main hallmark that distinguishes MV2 cases from VV2 is the presence of cerebellar Kuru-type amyloid plaques in the Purkinje cell layer (positive for Congo Red and Thioflavin-S) (Figure 2 E,F).

\section{MM2-thalamic subtype}

MM2-thalamic (MM2T) sCJD is a rare subtype (2\% of all the cases) known also as sporadic fatal insomnia (sFI). ${ }^{34,35}$ Biochemical characterization shows type $2 \mathrm{PrP}^{\mathrm{Sc}}$ with a predominant mono-glycosylated isoform. The mean age at onset is around 52 years (range 26-71 years) with a mean duration of 16 months (range 8-36 months). Besides insomnia, other common symptoms include dementia, and motor signs as ataxia, dysarthria, tremor, myoclonus and spasticity. ${ }^{34,36}$ Thalamus is the most affected brain region especially in the medial dorsal and anterior ventral nuclei where marked atrophy (observed also in the inferior olivary nucleus) and severe astrogliosis is accompanied by prominent neuronal loss. Spongiform changes and faint $\mathrm{PrP}^{\mathrm{Sc}}$ deposition may be present in the cerebral cortex.

\section{MM2-cortical subtype}

This rare cortical variant of MM2 subtype (type $2 \mathrm{PrP}^{\mathrm{Sc}}$ with a prevalence of the mono-glycosylated band) represents $2 \%$ of all SCJD cases and is characterized by progressive dementia and disturbances of higher cognitive functions, high-frequency aphasia and apraxia and late myoclonus or epileptic seizures. ${ }^{37}$ The average age at onset is 64 years with a 49-77 year range and the disease duration is approximately 16 months. Brain lesions are similar to that of MM1 or MV1 subtypes but, despite the relatively long disease duration, the cerebellum is almost spared. Large vacuoles are present in the cerebral cortex, basal ganglia and thalamus which might be confluent. Immunodetection of $\mathrm{PrP}^{\mathrm{Sc}}$ reveals a coarse pattern of staining which occasionally localizes at the rim of the vacuoles (perivacuolar $\mathrm{PrP}^{\mathrm{Sc}}$ deposition) (Figure $\left.2 \mathrm{G}, \mathrm{H}\right){ }^{31}$

\section{VV1 subtype}

VV1 is the rarest subtype of SCJD representing $1 \%$ of the total cases. The Western blot analysis shows type $1 \mathrm{PrP}^{\mathrm{Sc}}$ with a prevalence of the mono-glycosylated isoform. Patients are relatively younger (mean age at onset 44 years) compared to other sCJD subtypes with a mean duration of 21 months (range 17-42 months). Early symptoms include psychiatric or cognitive abnormalities that evolve in extrapyramidal signs and ataxia while myoclonus was observed only in few patients. Massive spongiform lesions affect the cortico-striatal regions while other subcortical regions and cerebellum are almost spared. Although the severe spongiform changes observed in VV1 patients, $\mathrm{PrP}^{\mathrm{Sc}}$ immunochemistry shows faint punctate staining confined in the cerebral cortex. ${ }^{31}$

\section{Mixed subtypes}

Type 1 and type $2 \mathrm{PrP}^{\mathrm{Sc}}$ have been found to co-exist in about $35 \%$ of sCJD cases and may be present in the same or distinct anatomical regions of the same patient. ${ }^{29}$ This finding is more frequent in MM (43\%) than MV (23\%) and VV (15\%) cases. ${ }^{14}$ The predominance of $\mathrm{PrPSc}^{\mathrm{Sc}}$ type 1 or 2 influences the clinical and neuropathological phenotype of the diseases. The MM1+2 cases mimic the clinical phenotype of MM1 while the $\mathrm{PrP}^{\mathrm{Sc}}$ deposition is a combination of the typical neuropathological features of MM1 and MM2 (synaptic and perivacuolar patterns, respectively). Conversely, VV1+2 subjects are similar to VV2 sCJD cases in terms of clinical and neuropathological features. ${ }^{14}$

Table 1. Pathological features of sCJD molecular subtypes.

\begin{tabular}{|c|c|c|c|c|}
\hline $\begin{array}{l}\text { sCJD } \\
\text { molecular } \\
\text { subtypes }\end{array}$ & $\begin{array}{l}\% \text { of } \\
\text { cases }\end{array}$ & $\begin{array}{c}\text { Median age } \\
\text { at onset } \\
\text { (years) }\end{array}$ & $\begin{array}{l}\text { Duration } \\
\text { (months) }\end{array}$ & Main neuropathological alterations \\
\hline MM1 & 67 & 66 & $\sim 4$ & $\begin{array}{l}\text { Diffuse spongiosis with small vacuoles affecting the neocortex, } \\
\text { striatum and cerebellar cortex. Synaptic pattern of PrPsc deposition }\end{array}$ \\
\hline MV1 & 3 & 66 & $\sim 4$ & \\
\hline W1 & 1 & 44 & $\sim 21$ & $\begin{array}{l}\text { Severe spongiosis with fine vacuoles in the cerebral cortex and striatum. } \\
\text { Punctate pattern of PrPsc deposition }\end{array}$ \\
\hline MM2 - thalamic & c 2 & 52 & $\sim 16$ & $\begin{array}{l}\text { Atrophy of the thalamus and inferior olivary nuclei with spongiform alterations } \\
\text { confined to the cerebral cortex. Weak and synaptic pattern of PrPsc deposition. }\end{array}$ \\
\hline MM2 - cortical & 2 & 64 & $\sim 16$ & $\begin{array}{l}\text { Severe spongiosis with large confluent vacuoles predominantly in cerebral cortex } \\
\text { and striatum. Perivacuolar and coarse pattern of PrPsc deposition. }\end{array}$ \\
\hline MV2 & 10 & 65 & $\sim 17$ & $\begin{array}{l}\text { Diffuse and confluent spongiosis similar to W2 subtype. Amyloid Kuru plaques in } \\
\text { the molecular and granular layer of the cerebellum. }\end{array}$ \\
\hline W2 & 15 & 64 & $\sim 7$ & $\begin{array}{l}\text { Spongiform changes found in the cerebellum, striatum, thalamus and brainstem. } \\
\text { Plaque-like and perineuronal pattern of PrPsc deposition. }\end{array}$ \\
\hline
\end{tabular}

MM1, Methionine/Methionine - PrPsc type 1; MV1, Methionine/Naline - PrPsc type 1; W1, Valine/Naline - PrPsc type 1; MM2-T, Methionine/Methionine - Thalamic PrPsc type 2; MV2-C, Methionine/Naline Cortical - PrPsc type 2; MV2, Methionine/Naline PrPsc type 2; W2, ValineNaline PrPsc type 2. 


\section{Clinical challenges}

The clinical diagnosis of SCJD is particularly challenging especially in the early stages of the disease. ${ }^{38}$ It relies on defined criteria that classify the disease as possible or probable. ${ }^{39}$ Several clinical, instrumental and laboratory tests are commonly used to formulate an in vivo diagnosis of sCJD: electroencephalogram (EEG), ${ }^{40}$ magnetic resonance imaging (MRI) ${ }^{41}$ and cerebrospinal fluid (CSF) biomarkers analysis. Several CSF biomarkers have been investigated including the 14-3-3 protein, total tau (t-tau) and phosphorylated tau ( $\mathrm{p}$-tau) proteins, neurofilament light chain (NfL), neuronspecific enolase and $\alpha$-synuclein. The most reliable and commonly used are 14-3-3 and t-tau. ${ }^{42,43}$

14-3-3 protein is a biomarker of neuronal cell death and therefore it is not specific for prion diseases. It is commonly reported to possess an average sensitivity of $85-95 \%$ and specificity of $40-$ $100 \%{ }^{32,44-48}$ for sCJD. However, the main issue in using the 14-3-3 as a biomarker for prion diseases lies in the fact that its elevation is common in some neurologic and neurodegenerative diseases including herpes simplex encephalitis, other encephalitis, intracerebral metastases, metabolic encephalopathy, hypoxic brain damage, dementia with Lewy bodies (DLB) and Alzheimer's disease (AD). ${ }^{33,49-51}$ Therefore, 14-3-3 analysis may increase the probability of CJD when other clinical features are suggestive of prion disease but it cannot be assumed as a specific biomarker. ${ }^{52}$

Increased levels of t-tau (cut off $>1300 \mathrm{pg} / \mathrm{mL}$ ) may identify sCJD patients with a sensitivity of $67-91 \%$ and a specificity of $67-$ 95\%. ${ }^{44,46,47,53-56}$ This measurement helps to differentiate sCJD from AD. Indeed, t-tau was 3.1 times higher in SCJD compared to AD and 41 times higher than in healthy subjects. ${ }^{57}$ Recently, the ratio $\mathrm{t}$-tau/p-tau was found elevated in SCJD patients with a specificity of $94-97 \%$ and a sensitivity ranging from $75-94 \% .{ }^{46,58-60}$

Among other CSF biomarkers proposed for prion disease diagnosis, NfL has been reported to be significantly elevated in SCJD compared to other neurodegenerative disorders like AD, DLB, frontotemporal dementia and vascular dementia. However, despite increased NfL levels enable discrimination of sCJD from normal controls, ${ }^{61-64}$ they do not consent accurate discrimination between SCJD and other rapidly progressive dementias ${ }^{65}$ neurodegenerative dementia ${ }^{64}$ and neurological diseases with dementia syndromes. ${ }^{62}$ Recently, serum NfL analysis has been suggested as a diagnostic marker for prion diseases showing similar sensitivity and specificity to CSF markers in differentiating SCJD from healthy subjects. ${ }^{66,67}$

$\alpha$-synuclein ( $\alpha$-syn) is commonly used as a biomarker for a group of diseases known as $\alpha$-synucleinopathies, which includes, among the others, Parkinson's disease (PD) ${ }^{68}$ and dementia with Lewy bodies (DLB), ${ }^{69}$ but its usefulness for CJD diagnosis has been recently investigated. Two studies reported that total $\alpha$-syn (t$\alpha$-syn) was specifically elevated in CSF of sCJD patients compared to control subjects..$^{70,71}$ Similarly, the phospho-serine-129 $\alpha$-synuclein (p- $\alpha$-syn) was found elevated in the CSF of sCJD patients compared to PD, DLB and neurological controls. A combined analysis of both markers, showed $90.5 \%$ sensitivity and $97.6 \%$ specificity for SCJD diagnosis. ${ }^{72}$ Other CSF and serum biomarkers of prion diseases, including the neuron specific enolase (NSE), ${ }^{73,74}$ the S100B protein, ${ }^{75}$ SERPINA $3^{76}$ and thymosin $\beta 4^{77}$ are currently under investigation. Unfortunately, although useful for the clinical diagnosis of CJD, CSF biomarkers are not disease-specific.

The definite diagnosis depends on post-mortem examination of the brain aimed at identifying and characterizing the disease-specific biomarker of prion diseases, the $\mathrm{PrPSc}^{\mathrm{Sc}}$. Through a combination of biochemical (e.g., Western blot after PK digestion), immunohistochemical and genetic analyses it is possible to identify the specific sCJD subtype. Thanks to the recent development of the ultrasensitive seeding aggregation assays, named Real-Time Quaking Induced Conversion (RT-QuIC) and Protein Misfolding Cyclic Amplification (PMCA) the diagnostic accuracy of prion diseases has been significantly increased. In particular, the PMCA enabled efficient detection of traces of $\mathrm{PrPsc}^{\mathrm{Sc}}$ in the $\mathrm{CSF}$, urine and blood of patients with variant CJD (vCJD), which is related to the consumption of foodstuff obtained from cattle affected by bovine spongiform encephalopathy. However, this technique, has never been able to efficiently detect $\mathrm{PrP}^{\mathrm{Ps}}$ associated with sCJD. ${ }^{78-81} \mathrm{In}$ contrast, the RT-QuIC has been optimized to efficiently detect low amounts of SCJD prions in the CSF, olfactory mucosa and skin samples in a more rapid and safe manner (with respect to PMCA) while requiring a limited handling of the specimens and reducing the risk of their contamination. ${ }^{82-85}$ For this reason, the RT-QuIC has been adopted by several specialized centers for the analysis of biological samples collected from patients with suspected SCJD, as detailed in the next section.

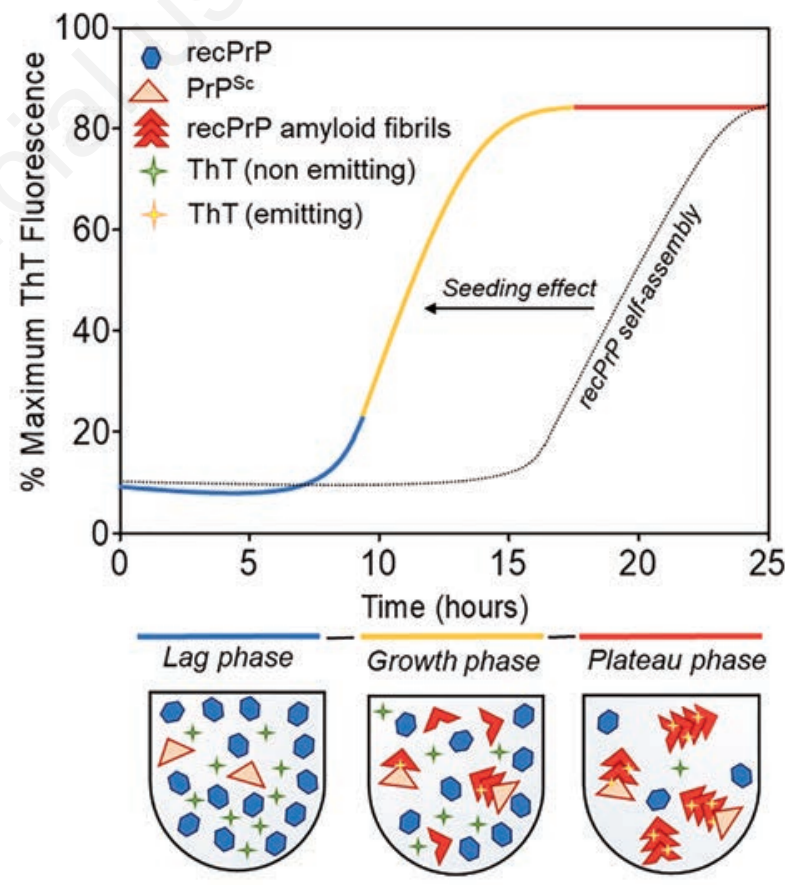

Figure 3. Schematic illustration of the RT-QuIC reaction. The RT-QuIC process is divided into three phases: (1) the lag phase, (2) the growth phase and (3) the plateau phase. The reaction mix is composed by recombinant $\operatorname{PrP}$ (recPrP) and Thioflavin $T$ (ThT) which are dissolved in common buffers. The addition of PrP $^{\text {Sc }}$ (pink triangle) to the reaction induces the convertion of recPrP (blue hexagon) into a misfolded form (red arrow) which starts to aggregate and form recPrP amyloid fibrils. In the absence of PrPsc, recPrP can aggregate (dotted line) following a well-defined kinetics. The formation of the aggregates induces the emission of a ThT fluorescence signal (yellow star). In the presence of PrPsc, the kinetics of recPrP aggregation is significantly accelerated (solid line). The increased kinetics of recPrP aggregation is known as seeding effect. 


\section{RT-QuIC assay}

RT-QuIC is an ultrasensitive technique developed by Atarashi et al. in 2011 in the field of prion diseases. This assay exploits the intrinsic ability of $\mathrm{PrP}^{\mathrm{Sc}}$ to promote the conformational rearrangement of $\operatorname{PrPC}^{\mathrm{C}}$ that can aggregate into amyloid fibrils. ${ }^{86}$ The assay mimics in vitro the process of $\mathrm{PrP}^{\mathrm{C}}$ misfolding and aggregation which occurs in vivo. Recombinant $\mathrm{PrP}^{\mathrm{C}}$ ( $\mathrm{rec} \mathrm{PrP}$ ) with the amino acid sequence of different species can be used as a reaction substrate. The addition of traces of $\mathrm{PrPSc}^{\mathrm{Sc}}$ to the reaction substrate induces its aggregation and the kinetics of this process can be monitored in real-time by using a fluorescent dye, named Thioflavin- $\mathrm{T}$ (ThT). ${ }^{87}$ In general, each sample is analyzed in quadruplicates using a multi-well plate. ${ }^{88}$ The samples are subjected to cyclic phases of incubation and shaking using a dedicated fluorescence microplate reader. ${ }^{89}$ In the presence of $\mathrm{PrP}^{\mathrm{Sc}}$, the incubation phase stimulates the formation of recPrP amyloid fibrils, while the shaking phase permits the fragmentation of the aggregates into smaller units capable to recruit and convert further recPrP into new amyloid fibrils..$^{90}$

The in vitro aggregation process can be represented on a cartesian plane where fluorescence is plotted against time generating a kinetic curve characterized by three phases: i) a lag phase, where $\mathrm{PrP}^{\mathrm{Sc}}$ interacts with recPrP and induces this latter to misfold ii) a growth phase, where misfolded recPrP aggregate to form oligomers and small amyloid fibrils sensitive to ThT (exponential increase of fluorescence) and iii) a plateau phase, where almost all recPrP is incorporated into fibrils. Under normal reaction conditions, recPrP spontaneously aggregates while the addition of $\mathrm{PrP}^{\mathrm{Sc}}$ (even in traces) to the substrate significantly accelerates the kinetic of recPrP aggregation (seeding effect) (Figure 3). A samples is considered positive when at least 2 out of 4 replicates show a seeding effect. The RT-QuIC end-products are partially resistant to PK digestion. $^{91}$

RT-QuIC enabled PrPSc detection in CSF, olfactory mucosa (OM), skin, eye, peripheral nerve, and digestive system of patients with different forms of prion diseases (Table 2).

The assay developed in 2011 was considered the "first generation RT-QuIC" since the analyses were performed at $42^{\circ} \mathrm{C}$ using the recombinant full-length Syrian Hamster prion protein $\left(\right.$ recSHa $\left._{(23-231)}\right)$ as reaction substrate. With this experimental setting it was possible to detect $\mathrm{PrPSc}^{\mathrm{Sc}}$ in the CSF of a series of Japanese subjects with SCJD and 30 Australian sCJD patients with $80 \%$ sensitivity and $100 \%$ specificity. ${ }^{92}$

One year later, the analyses of 123 patients with neuropathologically confirmed SCJD showed that RT-QuIC was able to identify $\mathrm{PrPS}^{\mathrm{Sc}}$ in CSF with a sensitivity of $91 \%$ and specificity of $98 \%{ }^{84}$

In 2014, Orrù and colleagues ${ }^{84}$ performed RT-QuIC analysis of $\mathrm{OM}$ and CSF collected from living patients with possible or probable clinical diagnosis of CJD. The RT-QuIC analysis of OM identified 30 out of 31 sCJD patients with a sensitivity of $97 \%$ and specificity of $100 \%$ while the analysis of CSF showed less sensi-

Table 2. Specificity and sensitivity of $1^{\text {st }}$ and $2^{\text {nd }}$ generation of RT-QuIC.

\begin{tabular}{|c|c|c|c|c|c|}
\hline Samples & Year & Reference & Substrate recPrP & Sensitivity \% & Specificity \% \\
\hline CSF & $\begin{array}{l}2011 \\
2012 \\
2014 \\
2015 \\
2015 \\
2016 \\
2016 \\
2016 \\
2016 \\
2016 \\
2017 \\
2017 \\
2017 \\
2017 \\
2017 \\
2017 \\
2018 \\
2018 \\
2019 \\
2019 \\
2020 \\
2020 \\
2020\end{array}$ & $\begin{array}{l}\text { Atarashi et al. }{ }^{82} \\
\text { McGuire et al. } .^{88} \\
\text { Orrù et al. }{ }^{84} \\
\text { Cramm et al. }{ }^{114} \\
\text { Orrù et al. }{ }^{115} \\
\text { Cramm et al. }{ }^{93} \\
\text { Groveman et al. }{ }^{94} \\
\text { Groveman et al. }{ }^{94} \\
\text { Park et al. }{ }^{95} \\
\text { McGuire } \text { et al. }{ }^{92} \\
\text { Franceschini } \text { et al. } .^{83} \\
\text { Bongianni et al. }{ }^{96} \\
\text { Bongianni et al. }{ }^{96} \\
\text { Lattanzio et al. }{ }^{56} \\
\text { Foutz et al. }{ }^{107} \\
\text { Foutz et al. }{ }^{107} \\
\text { Rudge et al. }{ }^{110} \\
\text { Hermann et al. }{ }^{109} \\
\text { Abu-Rumeileh et al. }{ }^{55} \\
\text { Abu-Rumeileh } \text { et al. }{ }^{55} \\
\text { Fiorini et al. }{ }^{100} \\
\text { Rhoads et al. }{ }^{97} \\
\text { Xiao et al. }{ }^{98}\end{array}$ & $\begin{array}{l}\text { recSHa }(23-231) \\
\text { recSHa }(23-231) \\
\text { recSHa }(23-231) \\
\text { recSHa }(23-231) \\
\text { recSHa }(90-231) \\
\text { recSHa }(23-231) \\
\text { recSHa }(23-231) \\
\text { recSHa }(90-231) \\
\text { recSHa }(23-231) \\
\text { recSHa }(23-231) \\
\text { recSHa }(90-231) \\
\text { recSHa }(23-231) \\
\text { recSHa }(90-231) \\
\text { recSHa }(23-231) \\
\text { recSHa }(90-231) \\
\text { recSHa }(90-231) \\
\text { recSHa }(23-231) \\
\text { recSHa }(23-231) \\
\text { recSHa }(23-231) \\
\text { recSHa }(90-231) \\
\text { recSHa }(90-231) \\
\text { recSHa }(90-231) \\
\text { recSHa }(90-231)\end{array}$ & $\begin{array}{c}91.5 \\
89.0 \\
77.0 \\
\text { Not reported } \\
95.8 \\
85.0 \\
72.5 \\
93.8 \\
76.5 \\
100.0 \\
97.2 \\
71.4 \\
82.6 \\
82.1 \\
92.0 \\
95.0 \\
89.0 \\
97.0 \\
82.5 \\
97.4 \\
96.0 \\
90.3 \\
96.7\end{array}$ & $\begin{array}{c}100.0 \\
99.0 \\
100.0 \\
\text { Not reported } \\
100.0 \\
99.0 \\
100.0 \\
100.0 \\
100.0 \\
100.0 \\
100.0 \\
100.0 \\
100.0 \\
99.4 \\
98.5 \\
100.0 \\
100.0 \\
99.0 \\
100.0 \\
100.0 \\
100.0 \\
98.5 \\
100.0\end{array}$ \\
\hline $\mathrm{OM}$ & $\begin{array}{l}2014 \\
2017 \\
2020\end{array}$ & $\begin{array}{l}\text { Orrù et al. }{ }^{84} \\
\text { Bongianni et al. }{ }^{96} \\
\text { Fiorini et al. }{ }^{100}\end{array}$ & $\begin{array}{l}\text { recSHa }(23-231) \\
\text { recSHa }(90-231) \\
\text { recSHa }(90-231)\end{array}$ & $\begin{array}{l}97.0 \\
92.0 \\
91.4\end{array}$ & $\begin{array}{l}100.0 \\
100.0 \\
100.0\end{array}$ \\
\hline Skin & $\begin{array}{l}2017 \\
2020\end{array}$ & $\begin{array}{c}\text { Orrù et al. }{ }^{105} \\
\text { Mammana et al. }{ }^{85}\end{array}$ & $\begin{array}{l}\text { recSHa }(23-231) \\
\text { recSHa }(23-231)\end{array}$ & $\begin{array}{c}100.0 \\
89.0\end{array}$ & $\begin{array}{l}100.0 \\
100.0\end{array}$ \\
\hline Eye & 2018 & Orrù et al. ${ }^{106}$ & recSHa (90-231) & 100.0 & 100.0 \\
\hline PN & 2019 & Baiardi et al. ${ }^{116}$ & recSHa $(90-231)$ & $100.0 \%$ & $100.0 \%$ \\
\hline DS & 2019 & Satoh et al. ${ }^{117}$ & not reported & $100.0 \%$ & not reported \\
\hline
\end{tabular}

CSF, cerebrospinal fluid; OM, olfactory mucosa; PN, peripheral nerve; DS, digestive system; recSHa ${ }_{(23-231)}$, recombinant full-length syrian hamster prion protein; recSHa ${ }_{(90-231)}$, recombinant $\mathrm{N}$-terminally truncated syrian hamster prion protein. 
tivity (77\%) but similar specificity (100\%). In 2016, the first multicenter studies demonstrated the reproducibility, reliability, and robustness of the first generation of CSF RT-QuIC (PQ-CSF) in clinical practice. ${ }^{92,93}$

In 2015, the group of Caughey optimized the RT-QuIC protocol and developed the "second generation RT-QuIC" by introducing two modifications: i) the use of N-terminally truncated recSHa $_{(90-231)}$ as a reaction substrate and ii) the increasing of temperature from $42^{\circ} \mathrm{C}$ to $55^{\circ} \mathrm{C}$. The use of a different substrate and a higher temperature improved the RT-QuIC performances by identifying positive CSF samples in shorter time (4-14 hours) compared to those required by the first generation assay (2,5-5 days). In particular, the RT-QuIC analysis identified $\mathrm{PrPSc}^{\mathrm{Sc}}$ in 46 out of 48 CSF samples collected from sCJD individuals yielding $95.8 \%$ diagnostic sensitivity and $100 \%$ specificity. Another retrospective study of Groveman et al. ${ }^{94}$ confirmed the high sensitivity and specificity (94\% and 100\%, respectively) of the CSF RT-QuIC test in a large cohort of patients $(n=113)$ with probable or definitive sCJD diagnosis. Further investigations were then performed with the aim of improving the sensitivity of the assay in detecting $\mathrm{PrP}^{\mathrm{Sc}}$ in CSF and OM. ${ }^{55,56,83,92,95-98}$ In 2020, an international trial confirmed the robustness and reliability of the second generation RTQuIC for the diagnosis of sCJD. ${ }^{99}$ Furthermore, a recent article by Fiorini et al. ${ }^{100}$ demonstrated that through the combined RT-QuIC analysis of the CSF and OM collected from the same sCJD patient it is possible to reach a diagnostic accuracy of $100 \%$. For these reasons, the RT-QuIC has been introduced among the diagnostic criteria of some surveillance centers. ${ }^{101}$ Recent evidence showed that recPrP with the bank vole amino acid sequence can detect almost all PrP strains (from human or animal origin), but it has not been introduced in the diagnostic field yet. ${ }^{102-104}$

From 2017, the RT-QuIC assay has been extended to the analysis of other peripheral tissues. In particular, Orrù et al. explored the potential prion seeding activity and infectivity of skin collected from $21 \mathrm{sCJD}$ patients and eye (retina, sclera and cornea) collected post-mortem from $11 \mathrm{sCJD}$ cases. ${ }^{105,106}$ Similarly, Mammama et al. analyzed skin biopsies of sCJD patients and identified $\mathrm{PrP}^{\mathrm{Sc}}$ with $89 \%$ sensitivity and $100 \%$ specificity. ${ }^{85}$

\section{Correlations of RT-QuIC results with neuropatho- logical findings}

To date, only few studies have investigated whether there is a correlation between the RT-QuIC results and the phenotypes of SCJD. ${ }^{107,108}$ In the case of CSF samples, the sensitivity of RT-QuIC was found to be high in the most common MM1/MV1 and VV2 sCJD cases, while it was lower in MV2 cases (75$93 \%) .{ }^{55,56,83,97,107,109}$ In other rare subtypes, including VV1 and MM2, the sensitivity was found to range between $0-100 \%$ and $44-$ $78 \%$, respectively. ${ }^{56,97,109-111}$ In these latter cases, the limited amount of CSF, hampered the possibility to properly evaluate the diagnostic accuracy of the assay. In 2016, Foutz et al. observed a correlation between RT-QuIC kinetics and SCJD subtypes. In particular, they observed that MM1 cases had significantly shorter lag phase and higher fluorescence values compared to MM2 cases, and these findings enabled discrimination of both phenotypes with an accuracy of $95 \%$. At the same time, the extended lag phase and lower intensity of fluorescence allowed to differentiate VV1 to VV2 individuals with an accuracy of $80 \%$. MV1, MV2, and mixed type cases did not show significant differences in terms of lag phases or fluorescence intensities. ${ }^{107}$ Recently, Piconi et al. subjected to PK digestion the RT-QuIC products obtained from the analysis of brain homogenates $(\mathrm{BH})$ and $\mathrm{CSF}$ of patients with the six phenotypes of sCJD. In this case, regardless of the sCJD subtype, all samples displayed PK-resistant signal characterized by similar electrophoretic mobility and banding profile, even when challenged with several anti-PrP antibodies. ${ }^{108}$ Thus, in contrast to the work of Foutz, they could not identify peculiar features useful to distinguish the six sCJD subtypes. For this reason, the possibility to identify SCJD subtypes by RT-QuIC remains to be clearly elucidated. Very recent findings show that formalin fixed brains are capable to exert an efficient seeding activity by RT-QuIC, using both animal ${ }^{112}$ and human specimens (personal communication).

\section{Conclusions}

Currently, the RT-QuIC test represents the most reliable and powerful tool for the early detection of $\mathrm{PrPSc}^{\mathrm{Sc}}$ in peripheral tissues of patients with a suspected clinical diagnosis of SCJD..$^{90}$ The reason for the rapid growth of RT-QuIC use in the clinical practice, although still confined to specialized laboratories, lays in the fact that it is not invasive for the patients, has a relatively low cost and a high predictive value. Among the advantages, the method is not time-consuming and enables the analysis of a huge number of samples in a relatively short period of time. ${ }^{113}$ Overall, these characteristics support the choice by WHO to include the CSF RT-QuIC test in the diagnostic criteria for SCJD..$^{39,99,101}$ As previously mentioned, only few specialized laboratories have adopted the RT-QuIC technology. However, the assay is relatively easy to learn and can be rapidly used by trained personnel, thus consenting its widening in other centers specialized in the diagnosis of neurodegenerative diseases associated with protein misfolding. Future multi-center trials will consent to verify the robustness of the RT-QuIC for the analysis of new peripheral tissues (e.g,. OM, skin) and to further explore the potential of this assay to stratify patients in their early disease stage.

\section{References}

1. Ladogana A, Puopolo M, Croes EA, Budka H, Jarius C, Collins S, et al. Mortality from Creutzfeldt-Jakob disease and related disorders in Europe, Australia, and Canada. Neurology 2005;64:1586-91.

2. Imran M, Mahmood S. An overview of human prion diseases. Virol J 2011;8:559.

3. Heidenhain A. [Klinische und anatomische Untersuchungen über eine eigenartige organische Erkrankung des Zentralnervensystems im Praesenium].[Article in German]. Z Gesamte Neurol Psy 1929;118:49-114.

4. Mittal M, Hammond N, Husmann K, Lele A, Pasnoor M. Creutzfeldt-Jakob disease presenting as bulbar palsy. Muscle Nerve 2010;42:833-5.

5. Alema G, Bignami A. [Subacute degenerative presenile polioencephalopathy with akinetic stupor and decorticate rigidity with myoclonus ("myoclonic" variety of the JakobCreutzfeld disease)].[Article in Italian]. Riv Sper Freniatr Med Leg Alien Ment 1959;83:S1485-623.

6. Nowacki P, Kulczycki J, Narolewska A, Grzelec H. Amyotrophic form of Creutzfeldt-Jakob disease with rapid course in 82-year-old man. Folia Neuropathol 2000;38:161-3.

7. Stahl N. Scrapie prion protein contains a phosphatidylinositol glycolipid. Cell 1987;51:229-40.

8. Castle AR, Gill AC. Physiological functions of the cellular prion protein. Front Mol Biosci 2017;4:19.

9. Turk E, Teplow DB, Hood LE, Prusiner SB. Purification and properties of the cellular and scrapie hamster prion proteins. 
Eur J Biochem 1988;176:21-30.

10. Caughey B, Race RE, Ernst D, Buchmeier MJ, Chesebro B. Prion protein biosynthesis in scrapie-infected and uninfected neuroblastoma cells. J Virol 1989;63:175-81.

11. Bate C, Nolan W, McHale-Owen H, Williams A. Sialic acid within the glycosylphosphatidylinositol anchor targets the cellular prion protein to synapses. J Biol Chem 2016;291:17093101.

12. Rudd PM, Endo T, Colominas C, Groth D, Wheeler SF, Harvey DJ, et al. Glycosylation differences between the normal and pathogenic prion protein isoforms. Proc Natl Acad Sci USA 1999;96:13044-9.

13. Oesch B, Westaway D, Wälchli M, McKinley MP, Kent SBH, Aebersold R, et al. A cellular gene encodes scrapie PrP 27-30 protein. Cell 1985;40:735-46.

14. Parchi P, Strammiello R, Notari S, Giese A, Langeveld JPM, Ladogana $\mathrm{A}$, et al. Incidence and spectrum of sporadic Creutzfeldt-Jakob disease variants with mixed phenotype and co-occurrence of PrPSc types: an updated classification. Acta Neuropathol 2009;118:659-71.

15. Soto C, Satani N. The intricate mechanisms of neurodegeneration in prion diseases. Trends Mol Med 2011;17:14-24.

16. Prusiner SB. Prions. Proc Natl Acad Sci USA 1998;95:1336383.

17. Soto C. Diagnosing prion diseases: needs, challenges and hopes. Nat Rev Microbiol 2004;2:809-19. A

18. Morales R, Hu PP, Duran-Aniotz C, Moda F, Diaz-Espinoza $\mathrm{R}$, Chen B, et al. Strain-dependent profile of misfolded prion protein aggregates. Sci Rep 2016;6:20526.

19. Rossi M, Baiardi S, Parchi P. Understanding prion strains: Evidence from studies of the disease forms affecting humans. Viruses 2019;11:309.

20. Morales R, Abid K, Soto C. The prion strain phenomenon: Molecular basis and unprecedented features. Biochim Biophys Acta 2007;1772:681-91.

21. Zafar S, Younas N, Shafiq M, Zerr I. Prion protein strain diversity and disease pathology. in: prions - Some physiological and pathophysiological aspects IntechOpen; 2019.

22. Parchi P, Giese A, Capellari S, Brown P, Schulz-Schaeffer W, Windl O, et al. Classification of sporadic Creutzfeldt-Jakob disease based on molecular and phenotypic analysis of 300 subjects. Ann Neurol 1999;46:224-33.

23. Hosszu LLP, Jackson GS, Trevitt CR, Jones S, Batchelor M, Bhelt $\mathrm{D}$, et al. The residue 129 polymorphism in human prion protein does not confer susceptibility to Creutzfeldt-Jakob disease by altering the structure or global stability of PrPc. J Biol Chem 2004; 279:28515-21.

24. Safar JG. Molecular pathogenesis of sporadic prion diseases in man. Prion 2012;6:108-15.

25. Kobayashi A, Iwasaki Y, Otsuka H, Yamada M, Yoshida M, Matsuura Y, et al. Deciphering the pathogenesis of sporadic Creutzfeldt-Jakob disease with codon $129 \mathrm{M} / \mathrm{V}$ and type 2 abnormal prion protein. Acta Neuropathol Commun 2013;1:74.

26. Kobayashi A, Teruya K, Matsuura Y, Shirai T, Nakamura Y, Yamada M, et al. The influence of PRNP polymorphisms on human prion disease susceptibility: an update. Acta Neuropathol 2015:130:159-70.

27. Uro-Coste E, Cassard H, Simon S, Lugan S, Bilheude JM, Perret-Liaudet A, et al. Beyond PrPres type 1/type 2 dichotomy in Creutzfeldt-Jakob disease. PLoS Pathog 2008;4:e1000029.

28. Cassard H, Huor A, Espinosa JC, Douet JY, Lugan S, Aron N, et al. Prions from sporadic Creutzfeldt-Jakob disease patients propagate as strain mixtures. MBio 2020;11:e00393-20.
29. Puoti G, Giaccone G, Rossi G, Canciani B, Bugiani O, Tagliavini F. Sporadic Creutzfeldt-Jakob disease: Co-occurrence of different types of PrPSc in the same brain. Neurology 1999;53:2173-6.

30. Zerr I, Schulz-Schaeffer WJ, Giese A, Bodemer M, Schröter A, Henkel K, et al. Current clinical diagnosis in CreutzfeldtJakob disease: Identification of uncommon variants. Ann Neurol 2000;48:323-9.

31. Parchi P, de Boni L, Saverioni D, Cohen ML, Ferrer I, Gambetti P, et al. Consensus classification of human prion disease histotypes allows reliable identification of molecular subtypes: an inter-rater study among surveillance centres in Europe and USA. Acta Neuropathol 2012;124:517-29.

32. Collins SJ. Determinants of diagnostic investigation sensitivities across the clinical spectrum of sporadic CreutzfeldtJakob disease. Brain 2006;129:2278-87.

33. Baiardi S, Magherini A, Capellari S, Redaelli V, Ladogana A, Rossi M, et al. Towards an early clinical diagnosis of sporadic CJD VV2 (ataxic type). J Neurol Neurosurg Psychiatry 2017;88:764-72.

34. Parchi P, Capellari S, Chin S, Schwarz HB, Schecter NP, Butts JD, et al. A subtype of sporadic prion disease mimicking fatal familial insomnia. Neurology 1999;52:1757-63.

35. Puoti G, Bizzi A, Forloni G, Safar JG, Tagliavini F, Gambetti P. Sporadic human prion diseases: molecular insights and diagnosis. Lancet Neurol 2012;11:618-28.

36. Scaravilli F, Cordery RJ, Kretzschmar H, Gambetti P, Brink B, Fritz V, et al. Sporadic fatal insomnia: A case study. Ann Neurol 2000;48:665-9.

37. Krasnianski A, Meissner B, Schulz-Schaeffer W, Kallenberg $\mathrm{K}$, Bartl M, Heinemann U, et al. Clinical features and diagnosis of the MM2 Cortical subtype of sporadic CreutzfeldtJakob disease. Arch Neurol 2006;63:876.

38. Mead S, Rudge P. CJD mimics and chameleons. Pract Neurol 2017;17:113-21.

39. Zerr I, Kallenberg K, Summers DM, Romero C, Taratuto A, Heinemann U, et al. Updated clinical diagnostic criteria for sporadic Creutzfeldt-Jakob disease. Brain 2009;132:2659-68

40. Zerr I, Pocchiari M, Collins S, Brandel JP, de Pedro Cuesta J, Knight RSG, et al. Analysis of EEG and CSF 14-3-3 proteins as aids to the diagnosis of Creutzfeldt-Jakob disease. Neurology 2000;55:811-5.

41. Collie DA, Sellar RJ, Zeidler M, Colchester ACF, Knight R, Will RG. MRI of Creutzfeldt-Jakob disease: Imaging features and recommended MRI protocol. Clin Radiol 2001;56:726-39.

42. Karch A, Zerr I. A comparison of tau and 14-3-3 protein in the diagnosis of Creutzfeldt-Jakob disease. Neurology 2013;80:2081.

43. Blennow K, Johansson A, Zetterberg H. Diagnostic value of 14-3-3 $\beta$ immunoblot and T-tau/P-tau ratio in clinically suspected Creutzfeldt-Jakob disease. Int $\mathrm{J}$ Mol Med 2005;16:1147-9.

44. Coulthart MB, Jansen GH, Olsen E, Godal DL, Connolly T, Choi BCK, et al. Diagnostic accuracy of cerebrospinal fluid protein markers for sporadic Creutzfeldt-Jakob disease in Canada: a 6-year prospective study. BMC Neurol 2011;11:133.

45. Chohan G, Pennington C, Mackenzie JM, Andrews M, Everington D, Will RG, et al. The role of cerebrospinal fluid 14-3-3 and other proteins in the diagnosis of sporadic Creutzfeldt-Jakob disease in the UK: a 10-year review. J Neurol Neurosurg Psychiatry 2010;81:1243-8.

46. Bahl JMC, Heegaard NHH, Falkenhorst G, Laursen H, Høgenhaven H, Mølbak K, et al. The diagnostic efficiency of biomarkers in sporadic Creutzfeldt-Jakob disease compared to 
Alzheimer's disease. Neurobiol Aging 2009;30:1834-41.

47. Sanchez-Juan P, Green A, Ladogana A, Cuadrado-Corrales N, Saanchez-Valle R, Mitrovaa E, et al. CSF tests in the differential diagnosis of Creutzfeldt-Jakob disease. Neurology 2006;67:637-43.

48. Stoeck K, Sanchez-Juan P, Gawinecka J, Green A, Ladogana A, Pocchiari M, et al. Cerebrospinal fluid biomarker supported diagnosis of Creutzfeldt-Jakob disease and rapid dementias: a longitudinal multicentre study over 10 years. Brain 2012;135:3051-61.

49. Satoh J, Kurohara K, Yukitake M, Kuroda Y. The 14-3-3 protein detectable in the cerebrospinal fluid of patients with prion-unrelated neurological diseases is expressed constitutively in neurons and glial cells in culture. Eur Neurol 1999;41:216-25.

50. Zerr I, Bodemer M, Gefeller O, Otto M, Poser S, Wiltfang J, et al. Detection of 14-3-3 protein in the cerebrospinal fluid supports the diagnosis of Creutzfeldt-Jakob disease. Ann Neurol 1998;43:32-40.

51. Chapman T, McKeel DW, Morris JC. Misleading results with the 14-3-3 assay for the diagnosis of Creutzfeldt-Jakob disease. Neurology 2000;55:1396-8.

52. Muayqil T, Gronseth G, Camicioli R. Evidence-based guideline: Diagnostic accuracy of CSF 14-3-3 protein in sporadic Creutzfeldt-Jakob disease: Report of the Guideline Development Subcommittee of the American Academy of Neurology. Neurology 2012;79:1499-506.

53. Hamlin C, Puoti G, Berri S, Sting E, Harris C, Cohen M, et al. A comparison of tau and 14-3-3 protein in the diagnosis of Creutzfeldt-Jakob disease. Neurology 2012;79:547-52.

54. Forner SA, Takada LT, Bettcher BM, Lobach I V., Tartaglia $\mathrm{MC}$, Torres-Chae $\mathrm{C}$, et al. Comparing CSF biomarkers and brain MRI in the diagnosis of sporadic Creutzfeldt-Jakob disease. Neurol Clin Pract 2015;5:116-25.

55. Abu-Rumeileh S, Baiardi S, Polischi B, Mammana A, Franceschini A, Green A, et al. Diagnostic value of surrogate CSF biomarkers for Creutzfeldt-Jakob disease in the era of RT-QuIC. J Neurol 2019;266:3136-43.

56. Lattanzio F, Abu-Rumeileh S, Franceschini A, Kai H, Amore G, Poggiolini I, et al. Prion-specific and surrogate CSF biomarkers in Creutzfeldt-Jakob disease: diagnostic accuracy in relation to molecular subtypes and analysis of neuropathological correlates of p-tau and A $\beta 42$ levels. Acta Neuropathol 2017;133:559-78.

57. Blennow K, Diaz-Lucena D, Zetterberg H, Villar-Pique A, Karch A, Vidal E, et al. CSF neurogranin as a neuronal damage marker in CJD: a comparative study with AD. J Neurol Neurosurg Psychiatry 2019;90:846-53.

58. Skillbäck T, Rosén C, Asztely F, Mattsson N, Blennow K, Zetterberg H. Diagnostic Performance of cerebrospinal fluid total tau and phosphorylated tau in Creutzfeldt-Jakob disease. JAMA Neurol 2014;71:476.

59. Baldeiras IE, Ribeiro MH, Pacheco P, Machado Á, Santana I, Cunha L, et al. Diagnostic value of CSF protein profile in a Portuguese population of SCJD patients. J Neurol 2009;256:1540-50.

60. Skinningsrud A, Stenset V, Gundersen AS, Fladby T. Cerebrospinal fluid markers in Creutzfeldt-Jakob disease. Cerebrospinal Fluid Res 2008;5:14.

61. Kovacs GG, Andreasson U, Liman V, Regelsberger G, Lutz MI, Danics K, et al. Plasma and cerebrospinal fluid tau and neurofilament concentrations in rapidly progressive neurological syndromes: a neuropathology-based cohort. Eur J Neurol 2017;24:1326-e77.

62. Zerr I, Schmitz M, Karch A, Villar-Piqué A, Kanata E,
Golanska E, et al. Cerebrospinal fluid neurofilament light levels in neurodegenerative dementia: Evaluation of diagnostic accuracy in the differential diagnosis of prion diseases. Alzheimer's Dement 2018;14:751-63.

63. Antonell A, Tort $\square$ Merino A, Ríos J, Balasa M, Borrego $\square$ Écija S, Auge JM, et al. Synaptic, axonal damage and inflammatory cerebrospinal fluid biomarkers in neurodegenerative dementias. Alzheimer's Dement 2020;16:262-72.

64. Abu-Rumeileh S, Capellari S, Stanzani-Maserati M, Polischi B, Martinelli P, Caroppo P, et al. The CSF neurofilament light signature in rapidly progressive neurodegenerative dementias. Alzheimers Res Ther 2018;10:3.

65. Kanata E, Golanska E, Villar-Piqué A, Karsanidou A, Dafou D, Xanthopoulos K, et al. Cerebrospinal fluid neurofilament light in suspected sporadic Creutzfeldt-Jakob disease. J Clin Neurosci 2019;60:124-7.

66. Steinacker P, Blennow K, Halbgebauer S, Shi S, Ruf V, Oeckl $\mathrm{P}$, et al. Neurofilaments in blood and CSF for diagnosis and prediction of onset in Creutzfeldt-Jakob disease. Sci Rep 2016;6:38737.

67. Thompson AGB, Luk C, Heslegrave AJ, Zetterberg H, Mead $\mathrm{SH}$, Collinge J, et al. Neurofilament light chain and tau concentrations are markedly increased in the serum of patients with sporadic Creutzfeldt-Jakob disease, and tau correlates with rate of disease progression. J Neurol Neurosurg Psychiatry 2018;89:955-61.

68. Gao L, Tang H, Nie K, Wang L, Zhao J, Gan R, et al. Cerebrospinal fluid alpha-synuclein as a biomarker for Parkinson's disease diagnosis: a systematic review and metaanalysis. Int J Neurosci 2015;125:645-54.

69. Bousiges O, Philippi N, Lavaux T, Perret-Liaudet A, Lachmann I, Schaeffer-Agalède C, et al. Differential diagnostic value of total alpha-synuclein assay in the cerebrospinal fluid between Alzheimer's disease and dementia with Lewy bodies from the prodromal stage. Alzheimers Res Ther 2020;12:120.

70. Llorens F, Kruse N, Karch A, Schmitz M, Zafar S, Gotzmann $\mathrm{N}$, et al. Validation of $\alpha$-synuclein as a CSF biomarker for sporadic Creutzfeldt-Jakob disease. Mol Neurobiol 2018;55:2249-57.

71. Llorens F, Kruse N, Schmitz M, Gotzmann N, Golanska E, Thüne $\mathrm{K}$, et al. Evaluation of $\alpha$-synuclein as a novel cerebrospinal fluid biomarker in different forms of prion diseases. Alzheimer's Dement 2017;13:710-9.

72. Schmitz M, Villar-Piqué A, Llorens F, Gmitterová K, Hermann P, Varges D, et al. Cerebrospinal fluid total and phosphorylated $\alpha$-synuclein in patients with CreutzfeldtJakob disease and synucleinopathy. Mol Neurobiol 2019;56:3476-83.

73. Aksamit AJ, Preissner CM, Homburger HA. Quantitation of 14-3-3 and neuron-specific enolase proteins in CSF in Creutzfeldt-Jakob disease. Neurology 2001;57:728-30.

74. Zerr I, Bodemer M, Räcker S, Grosche S, Poser S, Weber T, et al. Cerebrospinal fluid concentration of neuron-specific enolase in diagnosis of Creutzfeldt-Jakob disease. Lancet 1995;345:1609-10.

75. Otto M, Wiltfang J, Schutz E, Zerr I, Otto A, Pfahlberg A, et al. Diagnosis of Creutzfeldt-Jakob disease by measurement of S100 protein in serum: prospective case-control study. BMJ 1998;316:577-82.

76. Vanni S, Moda F, Zattoni M, Bistaffa E, De Cecco E, Rossi M, et al. Differential overexpression of SERPINA3 in human prion diseases. Sci Rep 2017;7:15637.

77. Le Pera M, Urso E, Sprovieri T, Bossio S, Aguglia U, Manna I, et al. Contribution of cerebrospinal fluid thymosin $\beta 4$ levels 
to the clinical differentiation of Creutzfeldt-Jakob disease. Arch Neurol. 2012;69(7):868-72.

78. Barria MA, Libori A, Mitchell G, Head MW. Susceptibility of human prion protein to conversion by chronic wasting disease prions. Emerg Infect Dis 2018;24:1482-9.

79. Moda F, Gambetti P, Notari S, Concha-Marambio L, Catania M, Park K-W, et al. Prions in the urine of patients with variant Creutzfeldt-Jakob disease. N Engl J Med 2014;371:530-9.

80. Concha-Marambio L, Pritzkow S, Moda F, Tagliavini F, Ironside JW, Schulz PE, et al. Detection of prions in blood from patients with variant Creutzfeldt-Jakob disease. Sci Transl Med 2016;8:370ra183.

81. Bélondrade M, Nicot S, Mayran C, Bruyere-Ostells L, Almela F, Di Bari MA, et al. Sensitive protein misfolding cyclic amplification of sporadic Creutzfeldt-Jakob disease prions is strongly seed and substrate dependent. Sci Rep 2021;11:4058.

82. Atarashi R, Satoh K, Sano K, Fuse T, Yamaguchi N, Ishibashi $\mathrm{D}$, et al. Ultrasensitive human prion detection in cerebrospinal fluid by real-time quaking-induced conversion. Nat Med 2011;17:175-8.

83. Franceschini A, Baiardi S, Hughson AG, McKenzie N, Moda F, Rossi M, et al. High diagnostic value of second generation CSF RT-QuIC across the wide spectrum of CJD prions. Sci Rep 2017;7:10655.

84. Orrú CD, Bongianni M, Tonoli G, Ferrari S, Hughson AG, Groveman BR, et al. A test for Creutzfeldt-Jakob disease using nasal brushings. N Engl J Med 2014;371:519-29.

85. Mammana A, Baiardi S, Rossi M, Franceschini A, Donadio V, Capellari S, et al. Detection of prions in skin punch biopsies of Creutzfeldt-akob disease patients. Ann Clin Transl Neurol 2020;7:559-64.

86. Cazzaniga FA, De Luca CMG, Bistaffa E, Consonni A, Legname G, Giaccone G, et al. Cell-free amplification of prions: Where do we stand? Prog Mol Biol Transl Sci 2020;175:325-58.

87. Schmitz M, Cramm M, Llorens F, Müller-Cramm D, Collins $\mathrm{S}$, Atarashi R, et al. The real-time quaking-induced conversion assay for detection of human prion disease and study of other protein misfolding diseases. Nat Protoc 2016;11:2233-42.

88. McGuire LI, Peden AH, Orrú CD, Wilham JM, Appleford NE, Mallinson $G$, et al. Real time quaking-induced conversion analysis of cerebrospinal fluid in sporadic Creutzfeldt-Jakob disease. Ann Neurol 2012;72:278-85.

89. Orrú C, Hughson A, Groveman B, Campbell K, Anson K, Manca M, et al. Factors that improve RT-QuIC detection of prion seeding activity. Viruses 2016;8:140.

90. Candelise N, Baiardi S, Franceschini A, Rossi M, Parchi P. Towards an improved early diagnosis of neurodegenerative diseases: the emerging role of in vitro conversion assays for protein amyloids. Acta Neuropathol Commun 2020;8:117.

91. Shaked GM, Fridlander G, Meiner Z, Taraboulos A, Gabizon R. Protease-resistant and detergent-insoluble prion protein is not necessarily associated with prion infectivity. J Biol Chem 1999;274:17981-6.

92. McGuire LI, Poleggi A, Poggiolini I, Suardi S, Grznarova K, Shi S, et al. Cerebrospinal fluid real-time quaking-induced conversion is a robust and reliable test for sporadic creutzfeldt-jakob disease: An international study. Ann Neurol 2016;80:160-5.

93. Cramm M, Schmitz M, Karch A, Mitrova E, Kuhn F, Schroeder B, et al. Stability and reproducibility underscore utility of RT-QuIC for diagnosis of Creutzfeldt-Jakob disease. Mol Neurobiol 2016;53:1896-904.

94. Groveman BR, Orrú CD, Hughson AG, Bongianni M, Fiorini $\mathrm{M}$, Imperiale D, et al. Extended and direct evaluation of RT-
QuIC assays for Creutzfeldt-Jakob disease diagnosis. Ann Clin Transl Neurol 2017;4:139-44.

95. Park J-H, Choi Y-G, Lee Y-J, Park S-J, Choi H-S, Choi K-C, et al. Real-Time Quaking-induced conversion analysis for the diagnosis of sporadic Creutzfeldt-Jakob disease in Korea. J Clin Neurol 2016;12:101.

96. Bongianni M, Orrù C, Groveman BR, Sacchetto L, Fiorini M, Tonoli G, et al. Diagnosis of human prion disease using realtime quaking-induced conversion testing of olfactory mucosa and cerebrospinal fluid samples. JAMA Neurol 2017;74:1562

97. Rhoads DD, Wrona A, Foutz A, Blevins J, Glisic K, Person M, et al. Diagnosis of prion diseases by RT-QuIC results in improved surveillance. Neurology 2020;95:e1017-26.

98. Xiao K, Yang XH, Zou WQ, Dong XP, Shi Q. Assessment of the sensitivity and specificity of the established real-time quaking-induced conversion (RT-QuIC) technique in Chinese CJD surveillance. Biomed Environ Sci 2020;33:620-2.

99. Orrú CD, Groveman BR, Foutz A, Bongianni M, Cardone F, McKenzie N, et al. Ring trial of 2nd generation RT-QuIC diagnostic tests for sporadic CJD. Ann Clin Transl Neurol 2020;7:2262-71.

100. Fiorini M, Iselle G, Perra D, Bongianni M, Capaldi S, Sacchetto L, et al. High diagnostic accuracy of RT-QuIC assay in a prospective study of patients with suspected SCJD. Int J Mol Sci 2020;21:880.

101. Hermann P, Laux M, Glatzel M, Matschke J, Knipper T, Goebel S, et al. Validation and utilization of amended diagnostic criteria in Creutzfeldt-Jakob disease surveillance. Neurology 2018;91:e331-8.

102. Redaelli V, Bistaffa E, Zanusso G, Salzano G, Sacchetto L, Rossi M, et al. detection of prion seeding activity in the olfactory mucosa of patients with fatal familial insomnia. Sci Rep 2017;7:46269.

103. Orrú CD, Groveman BR, Raymond LD, Hughson AG, Nonno $\mathrm{R}$, Zou W, et al. Bank vole prion protein as an apparently universal substrate for RT-QuIC-based detection and discrimination of prion strains. Supattapone S, editor. PLoS Pathog 2015; 11:e1004983.

104. Bistaffa E, Vuong TT, Cazzaniga FA, Tran L, Salzano G, Legname G, et al. Use of different RT-QuIC substrates for detecting CWD prions in the brain of Norwegian cervids. Sci Rep 2019;9:18595.

105. Orrú CD, Yuan J, Appleby BS, Li B, Li Y, Winner D, et al. Prion seeding activity and infectivity in skin samples from patients with sporadic Creutzfeldt-Jakob disease. Sci Trans1 Med 2017;9:eaam7785.

106. Orrù CD, Soldau K, Cordano C, Llibre-Guerra J, Green AJ, Sanchez H, et al. Prion seeds distribute throughout the eyes of sporadic Creutzfeldt-Jakob disease patients. MBio 2018;9:e02095-18.

107. Foutz A, Appleby BS, Hamlin C, Liu X, Yang S, Cohen Y, et al. Diagnostic and prognostic value of human prion detection in cerebrospinal fluid. Ann Neurol 2017;81:79-92.

108. Piconi G, Peden AH, Barria MA, Green AJE. Epitope mapping of the protease resistant products of RT-QuIC does not allow the discrimination of SCJD subtypes. PLoS One 2019;14:e0218509.

109. Hermann P, Appleby B, Brandel J-P, Caughey B, Collins S, Geschwind MD, et al. Biomarkers and diagnostic guidelines for sporadic Creutzfeldt-Jakob disease. Lancet Neurol 2021;20:235-46.

110. Rudge P, Hyare H, Green A, Collinge J, Mead S. Imaging and CSF analyses effectively distinguish CJD from its mimics. J Neurol Neurosurg Psychiatry 2018;89:461-6. 
111. Hayashi Y, Iwasaki Y, Yoshikura N, Asano T, Mimuro M, Kimura A, et al. An autopsy-verified case of steroid-responsive encephalopathy with convulsion and a false-positive result from the real-time quaking-induced conversion assay. Prion 2017;11:284-92.

112. Hoover CE, Davenport KA, Henderson DM, Pulscher LA, Mathiason CK, Zabel MD, et al. detection and quantification of cwd prions in fixed paraffin embedded tissues by real-time quaking-induced conversion. Sci Rep 2016;6:25098.

113. Green AJE. RT-QuIC: a new test for sporadic CJD. Pract Neurol 2019;19:49-55.

114. Cramm M, Schmitz M, Karch A, Zafar S, Varges D, Mitrova $\mathrm{E}$, et al. Characteristic CSF prion seeding efficiency in humans with prion diseases. Mol Neurobiol 2015;51:396-405.

115. Orrú CD, Groveman BR, Hughson AG, Zanusso G, Coulthart MB, Caughey B. Rapid and sensitive RT-QuIC detection of human Creutzfeldt-Jakob disease using cerebrospinal fluid. MBio 2015;6:e2451-14.

116. Baiardi S, Redaelli V, Ripellino P, Rossi M, Franceschini A, Moggio M, et al. Prion-related peripheral neuropathy in sporadic Creutzfeldt-Jakob disease. J Neurol Neurosurg Psychiatry 2019;90:424-7.

117. Satoh K, Fuse T, Nonaka T, Dong T, Takao M, Nakagaki T, et al. Postmortem quantitative analysis of prion seeding activity in the digestive system. Molecules 2019;24:4601. 